\title{
Use of Religion: An Effective Method of Coping among Chinese Patients with Cancer
}

\author{
Huaxia Liu1 ${ }^{*}$, Hongwei Shi', Qianqian Yang1, Aletha Rowlands' ${ }^{2}$, Minghua Han ${ }^{3}$ \\ ${ }^{1}$ School of Nursing, Taishan Medical University, Taian, China \\ ${ }^{2}$ School of Nursing, West Virginia University, Morgantown, USA \\ ${ }^{3}$ Taishan Vocational College of Nursing, Taian, China \\ Email: "
}

Received 24 September 2015; accepted 23 October 2015; published 26 October 2015

Copyright (C) 2015 by authors and Scientific Research Publishing Inc.

This work is licensed under the Creative Commons Attribution International License (CC BY). http://creativecommons.org/licenses/by/4.0/

(c) (i) Open Access

\section{Abstract}

Religion and/or spirituality (R/S) plays a variety of important and inter-related roles for most advanced cancer patients. It has confirmed that religious involvement helps the patients to ease stress and provides individuals with positive coping strategies. However, much less attention has been given to how religion has been used to cope with cancer in China. The aim of this study was to explore the self-adjustment and experiences of religious coping among Chinese patients with cancer. A qualitative descriptive approach was chosen for this investigation. 16 Chinese patients with cancer were recruited from 4 hospitals in Tai'an, Shandong, China from April 2013 to October 2013 and completed 0.5 - 1 hour of in-depth interviews. Data were analyzed by modification of Colaizzi's phenomenological method. Three themes were derived from the experiences of the participants: 1) self-adjustment including cognitive adjustment, faith adjustment and behavior adjustment; 2 ) the experience of religion coping with the cancer patients including emotional, physical and social aspect; 3 ) hope and power including the hope to heal, to survive from cancer, and to live longer, the cure, the spiritual supporter and the helper. The use of religion is an effective method for patients coping with cancer. Cancer patients use religion to obtain physiological, psychological, and spiritual comfort. Such knowledge is imperative for evidence-based nursing practice. As point of care providers, staff nurses are well poised to design systems and processes to accomplish the goals of providing excellent nursing care, which is reflective of a holistic and multicultural environment.

\section{Keywords}

Cancer, Religious Belief, Coping, Qualitative Analysis, Phenomenological Method

\footnotetext{
${ }^{*}$ Corresponding author.
}

How to cite this paper: Liu, H.X., Shi, H.W., Yang, Q.Q., Rowlands, A. and Han, M.H. (2015) Use of Religion: An Effective Method of Coping among Chinese Patients with Cancer. Open Journal of Nursing, 5, 893-899. 


\section{Introduction}

Cancer has become a serious threat to public health. In China, cancer has become the leading cause of death in urban areas and the second most common form of death in rural areas [1]. Nearly all medical treatments for cancer such as chemotherapy and radiation have negative side effects that may threaten the lives of cancer patients [2]. In addition to the physical burden of cancer, psychological distress, including increased anxiety and depression and poor quality of life, seems to be greater in cancer patients than in the general population, particularly among patients with later stage cancers [3]-[5]. Religious coping refers to the use of religious beliefs or practices to cope with stressful life circumstance [6] [7]. Religion and/or spirituality(R/S) plays a variety of important and inter-related roles for most advanced cancer patients [8]-[10]. It has confirmed that religious involvement helps the patients to ease stress and provides individuals with positive coping strategies [11]. The study on the relationship between religion and cancer began in the 1990s which had gradually become a key topic in nursing, especially in the field of hospice care and palliative care [12]. Nowadays approximately $50 \%$ $95 \%$ of cancer patients use religion to cope with disease, particularly among ethnic minorities, women, and older adults [13]. Although research has indicated that religious coping has a significant impact on patients' response to cancer, nothing is known about how Chinese cancer patients cope with cancer. This study employed a qualitative descriptive approach to examine how the patients used religion to cope with cancer, the function of religious coping, the factors influencing how cancer patients coped with religion and the experiences of individuals diagnosed with cancer in order to gain a more in-depth understanding of the religious coping in the context of Chinese culture. This study was based on two theoretical models within the spirituality literately: the general-attribution theory, behavioral-cognitive mechanisms and a meditational model [14] [15]. Results from this study may help health-care providers to facilitate their patients' spiritual journeys in dealing with their diagnoses and treatments.

\section{Methods}

A qualitative phenomenological approach was chosen to examine experiences of religious coping in patients with cancer. The purpose of phenomenological method is to uncover the genuine experience of the phenomenon under investigation [16] [17]. Modification of Colaizzi's phenomenological method was used to analyze data.

\subsection{Sample}

About 200 patients with cancer were approached from Taishan Medical University Affiliated Hospital, Tai'an Central Hospital, Tai' an Tumor Hospital and PLA $88^{\text {th }}$ Hospital all in Tai'an, Shandong, China. But there were only 20 patients were eligible to the study ( 4 of them refused to attend the study). At last 16 participants were conducted by depth-interview from April 2013 to October 2013. Demographic data were collected from patients' charts to provide a context for understanding the experience of religious coping of cancer patients. The including criteria of participants were: 1) 18 years or older; 2) diagnosed cancer confirmed by a pathological exam; 3) conscious and able to express their own opinions; 4) believing in a religion. The criteria of exclusion for participants were: 1) having not any religion; 2) refusing to attend the study; 3 ) at termly-ill stage and unable to finish the interview. An oral informed consent was obtained from each participant.

\subsection{Data Collection}

Before each interview, the participant was informed of the purpose and the process of the study, the rights of the participants and the principle of confidentiality. The participant was assured that he/she could leave the research at any time without any obligation or penalty. Before the interview, the primary researcher entered the research environment as a trainee nurse in order to build a trust relationship with patients and created a harmonious, relaxed interview atmosphere. The first set of interviews was based on the following general questions: How are you feeling today? Did you attend church? The Interview Guideline begin with: "Do you have any religion?" If "yes", then to next: 1) What religion do you believe in? 2) How long have you believed in this religion? Did you start believing in this religion before or after getting cancer? 3) Why did you believe in religion? 4) What religious activities do you attend? 5) What changes have you had since you believed in religion? How do you think about diseases, health, death and meaning of life? 6) What influence does religion have on the treatment and rehabilitation of your disease? 7) What do you think about believing in religion generally? Each interview was conducted in patient's ward where no other individuals were present which lasted 30 to 60 minutes and was rec- 
orded using a digital recorder. At the end of each interview, the participant completed a "general situation questionnaire" and left his/her contact information in case the researchers needed clarification. Immediately after each interview, the researcher recorded the non-verbal behaviors of each participant. Each recorded interview was transcribed in a timely manner.

\subsection{Data Analysis}

Modification of Colaizzi's phenomenological method was used to analyze the transcripts of their interviews. The six steps are as follows:

1) All the descriptions are read in order to to acquire a sense of the whole.

2) From each transcript the significant statements and phrases were extracted.

3) Meanings were formulated from those significant statements and phrases.

4) Formulated meanings were organized into cluster themes.

5) Themes are integrated into an exhaustive description.

6) The validation of exhaustive description is sought by participants.

At Last, three themes and their sub-themes were discussed several times before the final decisions made among four researchers.

\subsection{Ethical Considerations}

The research was approved on May 16, 2012 by the ethics committee in the medical university where the researchers worked. After examining the clinical environment using a questionnaire, researchers requested nursing and medical staff to assist with participant recruitment. Through the word of mouth among the participants who were recruited early, additional patients who met the inclusion criteria were recruited. Verbal consent was obtained from all participants.

\section{Results}

\subsection{Sample Description}

The sample consisted of 10 females and 6 males with a mean age of 50.44 years (ranged between 26 and 63 years). Seven of them were diagnosed with lung cancer $(n=7,43.75 \%)$, three were diagnosed with breast cancer $(n=3,18.75 \%)$, two with gastrointestinal cancer, liver cancer, and ovarian cancer $(n=2,12.5 \%$, respectively). Six patients received primary school education, nine patients received secondary level education, and one patient received university education. More details are shown in Table 1.

\subsection{Findings}

Three themes about religious coping derived from the experiences of the participants include self-adjustment, dependence and support, and hope and power.

\subsubsection{Theme I: Self-Adjustment}

\section{1) Cognitive Adjustment}

Cognitive adjustment was the first step of self-adjustment among cancer patients. The participants expressed different perspectives of life, disease, and death, which helped them face the disease directly.

Some of the patients reconsidered the meaning of life. Different religions showed different explanations on the meaning of life. The meaning of life in Christianity is the glory of God and His forgiveness. On the other hand, the meaning of life in Buddhism is unremitting self-improvement.

For example, participant 7 stated: "I exhausted myself to make more money, which eventually dragged me down. Now I realized that the priority is to be healthy and have a happy family instead of money". Participant 13 said: "Instructed by God, I do my best to do everything well in life".

Some patients changed their perspective of sickness and death. Christian claims that anything in the universe was controlled by God. Disease is a test from God who offers patients hope and confidence to conquer the disease. For example, participant 12 noted: "Death is to go to the eternal life in heaven".

Participant 1 stated: "People believing in Buddhism will go to paradise after they die and death is the start of a new life". 
Table 1. Characteristic of 16 participants.

\begin{tabular}{|c|c|c|c|c|c|c|c|c|}
\hline No. & Gender & Age & $\begin{array}{l}\text { Marital } \\
\text { Status }\end{array}$ & $\begin{array}{l}\text { Monthly } \\
\text { Income } \\
\text { (CHY) }\end{array}$ & Medical Diagnosis & $\begin{array}{l}\text { Disease } \\
\text { Duration } \\
\text { (Months) }\end{array}$ & $\begin{array}{l}\text { Religious } \\
\text { Belief }\end{array}$ & $\begin{array}{l}\text { Belief Duration } \\
\text { (Months) }\end{array}$ \\
\hline 1 & female & 53 & married & $>2000$ & right lung cancer with thorax metastasis & 16 & Buddhism & 16 \\
\hline 2 & female & 49 & divorced & $>2000^{*}$ & ovarian cancer & 20 & Buddhism & 130 \\
\hline 3 & female & 26 & single & $1000-2000$ & ovarian cancer & 8 & Buddhism & 6 \\
\hline 4 & female & 52 & married & $>2000$ & lung cancer with brain metastasis & 16 & Christianity & 3 \\
\hline 5 & male & 59 & married & $1000-2000$ & right lung cancer with thorax metastasis & 20 & Christianity & 120 \\
\hline 6 & male & 50 & married & $1000-2000$ & gastrointestinal cancer & 15 & Christianity & 6 \\
\hline 7 & female & 41 & married & $<1000$ & $\begin{array}{l}\text { right breast cancer with post-operative } \\
\text { metastasis }\end{array}$ & 48 & Christianity & 160 \\
\hline 8 & male & 53 & married & $>2000$ & liver cancer: terminal stage & 60 & Christianity & 120 \\
\hline 9 & male & 46 & married & $<1000$ & lung cancer with thorax metastasis & 36 & Christianity & 24 \\
\hline 10 & female & 38 & married & $1000-2000$ & right breast cancer: postoperative & 10 & Christianity & 4 \\
\hline 11 & female & 58 & married & $1000-2000$ & lung cancer & 15 & Christianity & 10 \\
\hline 12 & female & 59 & married & $>2000$ & Liver cancer: terminal stage & 60 & Christianity & 56 \\
\hline 13 & male & 50 & married & $<1000$ & lung cancer with general metastasis & 18 & Christianity & 18 \\
\hline 14 & male & 51 & married & $1000-2000$ & esophageal cancer & 13 & Christianity & 13 \\
\hline 15 & female & 63 & married & $<1000$ & lung cancer & 20 & Christianity & 36 \\
\hline 16 & male & 59 & married & $>2000$ & rectal cancer & 24 & Christianity & 20 \\
\hline
\end{tabular}

\section{2) Faith Adjustment}

Religion was found to have stimulated cancer patients' desire to live and their ability to accept being sick and to cope with their sickness optimistically. Participant 5 affirmed: "God cured my disease through the hands of doctors. The only thing I should do is to follow the will of God." Participant 4 stated: "I have to adjust myself to fight against disease. Whether it is good or bad, time goes away. Why don't I live happily?"

\section{3) Behavior Adjustment}

This study found that religion can enhance self-control, which enabled some participants to life a normal life. Participant 7 said: "Now I don't take myself as a patient. I do everything I can and never count on others. I try to keep a peaceful mind." "Now I will try to control my temper and put myself in other's position".

Most of the participants transferred their pressures from self to religion. Participant 16: "I have given myself to the hospital and God. Let them help me solve these problems".

\subsubsection{Theme II: Experience of Religion Coping}

The experience of religion coping can be summarized in three aspects: the emotional aspect, the physical aspect, and the social aspect.

\section{1) The Emotional Aspect}

The participants described that belief is the subject of their spirit. They believed that belief had the infinite power from God, could reduce the psychological distress. When they felt hopeless, God offered comfort and dependence, which encouraged them to live. For example, participant 4 noted: "In this group, people would offer help to me no matter what difficulties I have. This makes me feel loved beyond my family. Patients have a desire to receive more encouragement and support".

During the interview, some patients even had a positive change in personality. For example, participant 6 stated: "After I believed in religion, my personality has changed a lot. I was very bad-tempered, but now I am as mild as sheep". Participant 9 noted: "I go to religious activities every Thursday. I like these activities very much. People communicate with each other and I feel relaxed physically and mentally ... throw away all the worries and stress".

Some reported an increased happiness while others demonstrated happiness. For example, participant 2 stated: "I am joyful and relaxed now". Participant 8 claimed: "I feel comfortable and happy everyday". 


\section{2) The Physical Aspect}

Religion was found to have played an important role in health restoration and as a healer. Participants responded that religion could not only ease the emotional and psychological discomfort, but also improve the symptom management. Religious activities could reduce the side effects of chemotherapy. For instance, participant 1 believed: "Buddhism can cure cancer and free me from pains".

\section{3) The Social Aspect}

Participants responded that religion could promote interpersonal relationships and promote family harmony. Participant 7 explained: "After I believed in religion, I was much more open-minded, didn't care about what other people talk about me, and felt less anxious when communicating with others". Participant 12 said: "I have been a Christian for more than 10 years". "I have a harmonious family. Others might wonder how my family could be happy every day when it had a cancer patient at home". Participant 5 explained: "Since I believe in Christen, I reflect my fault first. I then talk about my husband's. We both changed and stopped gambling. Now we are getting along very well".

\subsubsection{Theme III: Hope and Power}

Based on their own experiences, participants claimed that religion had provided them with hope to heal, to survive from cancer, and live longer. They also believed that religion had provided a source of internal power to fight cancer. Words, such as "hope", "super power", "peaceful", "relax", "helpful", "comfortable", "stable and pure", "confident" and "no fear of death or cancer" were mentioned frequently by participants.

\section{Discussion}

The present study described self-adjustments and experiences of religion coping among Chinese patients with cancer. We found that religious coping is an effective way to cope with difficult situations. It has the effects of psychological treatment and affects patient's psychological, mental and physical health. It is estimated that over 100 million people in China believe in religion, and a majority of them suffer from major illnesses. It is of great significance to examine the relationship between the religious belief and health and disease. This study used qualitative methods to describe the cancer patients' experiences of using religion to cope with cancer religious. This study revealed that religion coping is an important coping mechanism used by patients with cancer.

\subsection{General Condition of the Participants}

We faced some difficulties to recruit the eligible participants because most of patients said that they had no religion. Another point as seen in Table 1, a majority of the participants are female farmers with low level of education and lower income. The result supported Pargament and Smith' study [14]. They found in their study that women, the elderly, and the poor are more likely to choose religion to cope with life events due to their lack of alternative means to solve problems. Religious coping refers to the use of religious beliefs or practices to cope with stressful life circumstance [6] [7]. It goes through a series of changes ranging from knowledge acquisition to behavior modification. In this process, many factors can affect the transformation including patients' cognitive level, cultural background, social view of religion, and others. Any of those factors may influence the effect of religious coping.

\subsection{Self-Regulation}

This study found that religious belief had led patients with cancer to have a new understanding of the meaning of life, disease, and death. For example, they believed "disease is a kind of test; death is not the end of the individual existence." Such finding is consistent with what Frankl reported. In 1958, Frankl established the link between spirituality and finding meaning. Frank felt that people who believed in God had an even stronger sense of meaning in life, even in the face of adversity and death. Spiritual people who believe in God have a constant "invisible witness present" who expects something of them in any given circumstance [18]-[20]. This view provides a good explanation of "Why me" for patients, which can quickly reduce the fear of cancer and death so that they can face the cancer and actively participate in cancer treatment.

Many factors affected the cancer patients' emotional adjustment such as spiritual support and the social support from religious groups. Such supports help patients with cancer to face the disease directly, adjust their atti- 
tude, and face life with an optimistic and positive attitude [17].

In the process of behavior modification, the participants mainly use some religious activities to relieve the pain of body and mind. For example, prayer has been used to enhance the confidence of patients and transfer the attention of somatic symptoms. Repentance has been used to reduce their mental stress which is conducive to treating the body and mind of patients. Twisting beads is used to adjust the state of mind so that the state of mind is peaceful.

\subsection{Self Experience}

During the Interview, almost all of the participants described that belief was their spiritual sustenance and reliance. Belief was one of the biggest psychological comfort factors for them, especially when they were in great distress. Faith had become the biggest spiritual pillar in their life. For example, some patients said "I feel there is a powerful force that supports me", and "I feel God always encourage me at any time". Regarding God as their listener, participants expressed their inner feelings through prayers to reduce psychological distress. Some studies have shown that cry and talk can release chemicals caused by fear, grievances, anger and other negative emotions, which is conducive to patient's physical and mental health [21]. Religion can help patients to eliminate pain and improve their immune function. It is reported that some patients refuse conventional medical treatment. Instead, they use religion to relieve symptoms and cure the disease [22]. Although the exact mechanism of how religion can produce such effects is unknown, the cognition of religious follower may play a key role. The present study confirmed that the use of religion is an effective method for patients to cope with cancer. Nurses could guide the patients to use religion to cope, enhance cognition. The study also has some limitations: such as a small sample since less people having a religion in China. And the study belongs to the qualitative research lacking of long-term follow-up across groups.

\section{Conclusions}

The study explained the phenomenon of religious coping among Chinese patients with cancer. In this study, we found that the use of religion was an effective method for patients to cope with cancer. Patients with cancer can obtain physiological, psychological, and spiritual comfort by use of religion. Current mental care for cancer patients is inadequate. Cancer patients have more psychological needs than physical needs. They need much more comfort and support from family, medical staff and community. The results of the study may improve healthcare provider's understanding and recognition to the importance of religious coping among patients with cancer. And it may help health-care providers to facilitate their patients' spiritual journeys in dealing with cancer diagnoses and treatments. As point-of-care providers, staff nurses are well poised to design systems and processes to accomplish the goals of providing excellent nursing care in a holistic and multicultural environment.

The authors have no funding or conflicts of interest to disclose.

\section{References}

[1] Liu, J., Yang, X.L., Li, A., Chen, W.Q., Ji, L., Zhao, J., Yan, W., Chen, Y.Y. and Zhu, L.P. (2014) Epidemiological Patterns of Cancer Incidence in Southern China: Based on 6 Population-based Cancer Registries. Asian Pacific Journal of Cancer, 15, 1471-1475. http://dx.doi.org/10.7314/APJCP.2014.15.3.1471

[2] Massie, M.J. and Holland, J.C. (1987) Consultation and Liaison Issues in Cancer Care. Psychiatric Medicine, 5, 343359.

[3] Derogatis, L.R. and Melisaratos, N. (1983) The Brief Symptom Inventory: An Introductory Report. Psychological Medicine, 13, 596-605. http://dx.doi.org/10.1017/s0033291700048017

[4] Derogatis, L.R., Morrow, G.R., Fetting, J., Penman, D., Piasetsky, S., Schmale, A.M., Henrichs, M. and Carnicke, C.L. (1983) The Prevalence of Psychiatric Disorders among Cancer Patients. Journal of the American Medical Association, 249, 751-757. http://dx.doi.org/10.1001/jama.1983.03330300035030

[5] Kimberly, K.L., Sandra, G.Z. and John, P.B. (2004) The Role of Spirituality in the Psychological Adjustment to Cancer: A Test of the Transactional Model of Stress and Coping. International Journal of Behavioral Medicine, 11, 48-55. http://dx.doi.org/10.1207/s15327558ijbm1101_6

[6] Koening, H.G., Cohen, H.J., Blazer, D.G., Pieper, C., Meador, K.G., Shelp, F., Goli, V. and DiPasquale, B. (1992) Religious Coping and Depression among Elderly, Hospitalized Medically Ill Men. Annals of General Psychiatry, 149, 1639-1770. 
[7] Koenig, H.G., George, L.K. and Siegler, I.C. (1988) The Use of Religion and Other Emotion-Regulating Coping Strategies among Older Adults. Gerontologist, 28, 303-310. http://dx.doi.org/10.1093/geront/28.3.303

[8] Sara, R., Michael, J., Holly, G., Amy, R., Andrea, C., Alexi, A., Susan, D., John, R., Lisa, A. and Tracy, A. (2010) “If God Wanted Me Yesterday, I Wouldn't Be Here Today": Religious and Spiritual Themes in Patients' Experience of Advanced Cancer. Journal of Palliative Medicine, 13, 581-588. http://dx.doi.org/10.1089/jpm.2009.0343

[9] Astrow, A.B., Wexler, A., Texeira, K., He, M.K. and Sulmasy, D.P. (2007) Is Failure to Meet Spiritual Needs Associated with Cancer Patients' Perceptions of Quality of Care and Their Satisfaction with Care? Journal of Clinical Oncology, 25, 5753-5757. http://dx.doi.org/10.1200/JCO.2007.12.4362

[10] Moadel, A., Morgan, C., Fatone, A., Grennan, J., Carter, J., Laruffa, G., Skummy, A. and Dutcher, J. (1998) Seeking Meaning and Hope: Self-Reported Spiritual and Existential Needs among an Ethnically-Diverse Cancer Patient Population. Psychooncology, 8, 378-385. http://dx.doi.org/10.1002/(SICI)1099-1611(199909/10)8:5<378::AID-PON406>3.0.CO;2-A

[11] Holt, C.L., Qi, M. and Wang, L.C. (2011) Role of Religious Involvement and Spirituality in Functioning among African Americans with Cancer: Testing a Meditational Model. Journal of Behavioral Medicine, 34, 437-448. http://dx.doi.org/10.1007/s10865-010-9310-8

[12] Kune, G.A., Kune, S. and Watson, L.F. (1992) The Effect of Family History of Cancer, Religion, Parity and Migrant Status on Survival in Colorectal Cancer: The Melbourne Colorectal Cancer Study. European Journal of Cancer, 28, 1484-1487. http://dx.doi.org/10.1016/0959-8049(92)90549-H

[13] Abernethy, A.D., Chang, H.T., Seidlitz, L., Evinger, J.S. and Duberstein, P.R. (2002) Religious Coping and Depression among Spouses of People with Lung Cancer. Psychosomatics, 43, 456-463. http://dx.doi.org/10.1176/appi.psy.43.6.456

[14] Pargament, K.I. and Smith, B.W. (1998) Patterns of Positive and Negative Religious Coping with Major Life Stressors. Journal for the Scientific Study of Religion, 37, 710-724. http://dx.doi.org/10.2307/1388152

[15] Balboni, T.A., Vanderwerker, L.C. and Block, S.D. (2007) Religiousness and Spiritual Support among Advanced Cancer Patients and Associations with End of Life Treatment Preferences and Quality of Life. Journal of Clinical Oncology, 25, 555-560. http://dx.doi.org/10.1200/JCO.2006.07.9046

[16] Turunen, H., Perälä, M.L. and Meriläinen, P. (1994) Modification of Colaizzi's Phenomenological Method: A Study Concerning Quality Care. Hoitotiede, 6, 8-15.

[17] Moustakas, C. (1994) Phenomenological Research Method. Sage, London.

[18] Frankl, V.E. (1958) The Will to Meaning. Journal of Pastoral Care, 12, 82-88.

[19] Frankl, V.E. (1966) What Is Meant by Meaning? Journal of Existentialism, 6, 21-28.

[20] Albaugh, J.A. (2003) Spiritual and Life-Threatening Illness: A Phenomenologic Study. Oncology Nursing Forum, 30, 593-598. http://dx.doi.org/10.1188/03.ONF.593-598

[21] Lin, B. (2002) On the Psychological Function of Religious Belief. Journal of Fujian Teachers University, 2, 125-129. (In Chinese)

[22] Trevino, K.M., Balboni, M., Zollfrank, A., Balboni, T. and Prigerson, H.G. (2014) Negative Religious Coping as a Correlate of Suicidal Ideation in Patients with Advanced Cancer. Psychooncology, 23, 936-945. 